\title{
The System of Informational Choice of the Kinematic Scheme for the Formation of Shells of a Complex Spatial Form
}

\author{
V. Mikheev \\ Department of Metal Forming \\ Samara University, Samara, Russia \\ Corresponding author: vamicheev@ rambler.ru \\ A. Grechnikova \\ Department of Metal Forming \\ Samara University, Samara, Russia \\ E-mail: anna_gr17@yahoo.com \\ A. Roslyakov \\ Samara State Transport University, Samara, Russia \\ Information Center of SPbPU, Madrid, Spain \\ E-mail: roslykov_ad@mail.ru \\ D. Agafonova \\ Department of Metal Forming \\ Samara University, Samara, Russia \\ E-mail: dafna_agafonova@mail.ru
}

(Received November 25, 2018; Accepted May 11, 2019)

\begin{abstract}
Three kinematic schemes are studied, which differ from one another in the route of technological operations. Each of these kinematic schemes has its own set of power stages of shaping and stages of free bending or bending of the ends of the sheet blank. In addition, the quantitative values of the angular parameters of a particular kinematic scheme are determined. Numerical experiments have been carried out, which give complete information about the distribution of the shell thickness as discrete values in one or another element. The result is statistical processing of this information, the scope of the predicted values and comparison with the tolerance on the thickness of the peel used in aviation enterprises.
\end{abstract}

Keywords- Shell of significant double curvature, ANSYS, Distributions of experimental data.

\section{Introduction}

The tightening process in the domestic aircraft building industry is the main way to form shells of double curvature and has the same advantages as bending with stretching. Depending on the nature of the application of external forces, the tightening process at the initial stage of development in industry was divided conditionally into a simple hanging (OT scheme) and tightening with stretching (RO scheme) (Filin, 1987, Glouschenkov, 1997). Sometimes these tightening schemes are called respectively transverse and longitudinal. In turn, double curvature shells are divided into a number of characteristic groups, among which we select only the shells of a complex spatial form (Leishman et al., 2011, Rudskoy et al., 2016; Snegirev et al., 2018). These shells with significant curvature in both directions of biconvex form are made on presses of the OP type (Figure 1).

A simple covering is characterized in that the forming force $\mathrm{P}$ is applied to the punch, and the 
International Journal of Mathematical, Engineering and Management Sciences

Vol. 4, No. 4, 946-956, 2019

https://dx.doi.org/10.33889/IJMEMS.2019.4.4-075

tensile stresses in the sheet occur along the wide side of the workpiece due to the reaction forces $\mathrm{N}$ of the fixed clamps of the press. A simple hanging is used to produce curved short shells of considerable double curvature of biconvex form with large angles of coverage up to $180^{\circ}$. Tension presses type OP have a horizontal table with the arrangement of clamps along its side (long) sides (Miheev et al., 2003; Grechnikov et al., 2009; Vasilyev et al., 2017; Baimova et al., 2017; Stepanov et al., 2017). In the overwhelming majority of these presses have a lifting table, by moving it and tightening is done at fixed clamps (press OP-3). The horizontal table is mounted on two power cylinders that lift it.

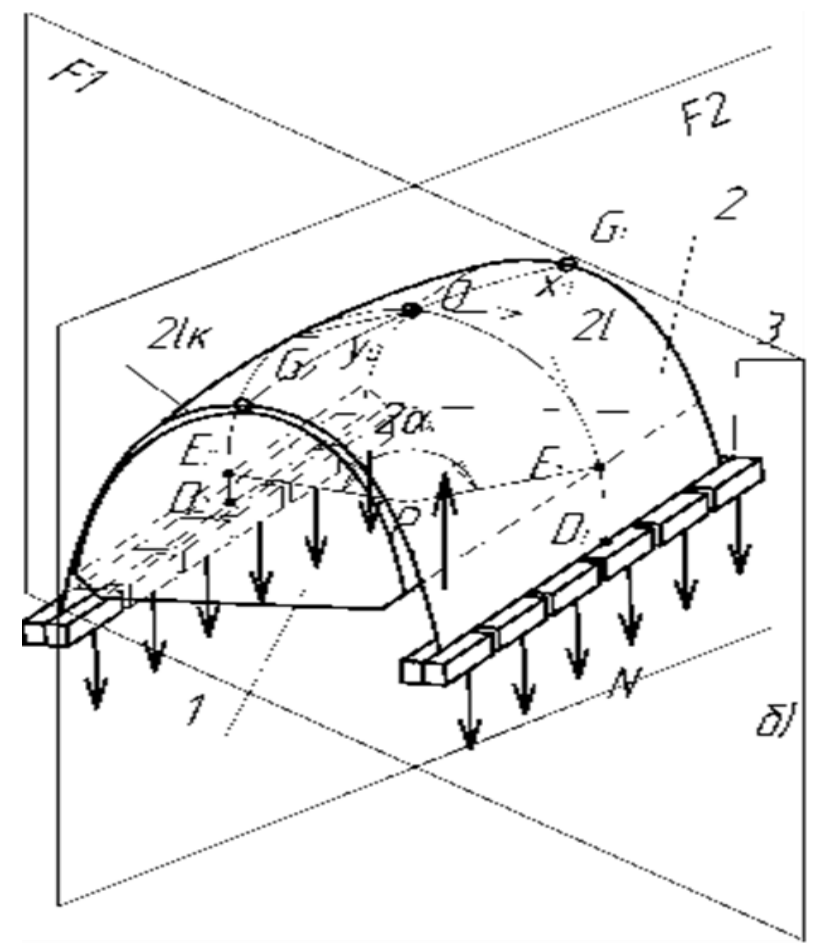

Figure 1. Scheme of the process of simple hanging over a tight punch of a shell of significant double curvature of a biconvex shape: 1 - punch; 2 - blank; 3 - press clamps

In recent years, the company ASV (France) is continuing work on the creation of new covered equipment, among which you can identify the presses of the transverse FET, longitudinal FEL and combined FETL actions (Imayev et al., 2016; Burkovsky et al., 2017, Kodzhaspirov and Rudskoi, 2017). On the FET press, there are rectilinear clamping jaws arranged horizontally. Movement clamping jaws on a certain pseudo trajectory is carried out by four hydraulic cylinders, of which two are horizontal, and two are vertical. These hydraulic cylinders form four connecting rods of variable length, pivotally attached to the common frame of the press (Apostolopoulos et al., 2017). In this case, the FET press table is fixed and installed for easy operation at the floor level (Figure 2). 
International Journal of Mathematical, Engineering and Management Sciences

Vol. 4, No. 4, 946-956, 2019

https://dx.doi.org/10.33889/IJMEMS.2019.4.4-075

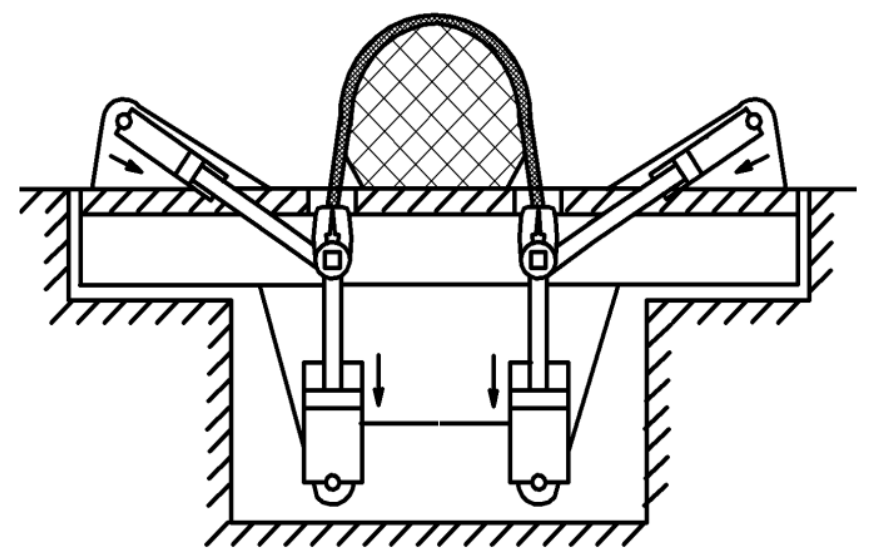

Figure 2. FET type pull press

As a result of the relative movements of the two parallel hydraulic cylinders, it becomes possible to move the clamping jaws both in a straight line and at an angle within the limits determined by the actions of the connecting rod mechanism. Eight programmable coordinates formed by moving the rods of the hydraulic cylinders from each side of the press table are simultaneously controlled by a special software control system with feedback (Izamshah et al., 2011; Musabirov et al., 2016; Ivanov, 2018). Collapsible presses with (numerical program management) $\mathrm{CNC}$ provide realization of various kinematic schemes of forming by the tightness of a shell of the complex spatial form. The choice of rational schemes is a key task of the information support system and is carried out depending on the geometric parameters of the shell, the limiting coefficient of the tightening and the type of the tightening equipment. To do this, it is necessary to collect information on the trajectory of the edges of the workpiece, on which the technological capabilities of the hanging process essentially depend on the degree of unevenness of the strain in the direction of the tightening (Grechnikov et al., 2015; Petrichenko et al., 2016, Smirnov et al., 2016).

A directional change in the thickness of the workpiece when it is formed into a shell with a minimum variance is carried out in a sequential manner, due to the optimal choice of the coverage angle in the first hooking operation: either from the total angle $\alpha \mathrm{k}$, or from the angle $\alpha 1$ to $\alpha$ by step loading. Changing the angle of coverage by an amount $\Delta \alpha 1$, for example, upwards, causes an additional deformation of the workpiece stretching along the boundary of its contact with the punch due to external friction, which from a certain moment can lead to the localization of deformation in the free section. Then, the shaping of the second curvature in the region of the central section is possible only from a certain angle of coverage a1 (Lisovenko et al., 2016; Galaev et al., 2017; Bulovich, 2017).

Correct selection of the initial angle of coverage $\alpha 1$ should ensure complete shaping of the workpiece in the central section passing through point $\mathrm{O}$ without deformation localization in the part of the blank that is not yet part of the workpiece between the exit from the punch and the press clamps. After preliminary tightening the flat workpiece from the angle $\alpha 1$ to the full angle of coverage $\alpha k$, the largest deformation will be in the region of the central section of the shell with Gaussian curvature at the point $\mathrm{O}$, the value of which is $k_{10} \cdot k_{20}$. 
International Journal of Mathematical, Engineering and Management Sciences

Vol. 4, No. 4, 946-956, 2019

https://dx.doi.org/10.33889/IJMEMS.2019.4.4-075

The Gaussian curvature will retain its value when the shell surface is bent in a load-free state, while the radii of curvature $R_{1}^{(O)}$ and $R_{2}^{(O)}$ during bending of the envelope change. Based on the above property of the internal geometry of the surfaces, a technological solution has been formed. It is suggested to unload the shell after the preliminary tightening and, without releasing it from the clamps, perform the bending of the shell by an angle $\alpha$ due to the movement of the press clamps along the calculated trajectory.

As a result, we obtain the so-called isometric shell surface with respect to the surface of the hanging punch with radii of curvature at the point $\mathrm{O}$, respectively, and connected by the relation for the same value of the Gaussian curvature $K_{0}$ :

$$
R_{2}^{(O)^{\prime}}=\frac{1}{K_{o} \cdot R_{1}^{(O)^{\prime}}},
$$

where, if the angle $R_{1}^{(O)}$ is increased by an angle $\alpha p$, then, on the contrary, decreases to $R_{1}^{(O)^{\prime}}$, and the shell retreats from the punch surface in the region of the central section by an amount $f_{p}$.

During the subsequent tightening of the shell with the isometric shape of the surface by step loading from the angle $\alpha p$ to $\alpha k$, as a result of the transformation of the deformation focus due to the change in the boundary conditions, the edge underformed parts of the preform are stretched and the conditions for equalizing the thickness of the workpiece in the transverse direction are created.

Thus, the internal parameters of the sequential forming pattern of the skin-tightness are the kinematic angular values associated with the angle of coverage of the tightening punch and with the angle of extension of the shell between the operations of the hanging (Rudskoy et al., 2016a; Rudskoy et al., 2016b; Andreeva et al., 2016). The choice of angular parameter values is realized due to the understanding of several reasons:

(i) The localization of the deforming forces in the region of the pole of the tight punch at the first hooking operation is taken into account due to the presence of flat sections in the area of the workpiece removal from the punch. In this case, this localization can be considered as the effect of a "direct descent" of the workpiece, charged with a rectilinear row of clamp bodies (Rudskoi et al., 2016; Politova et al., 2019). Therefore, the angle of coverage for the first reason is chosen equal to $90^{\circ}$ with the presence of an undercut of the press clamping unit.

(ii) The features of the formation of the central portion of the shell at the initial stage of the first hooking operation are taken into account, on which the localization of the deforming forces in the vicinity of the pole of the tight punch is preserved. The central section of the shell is characterized by certain angular parameters with respect to the pole. First of all, this is the angle that is $18^{\circ}$ and the angle equal to $7^{\circ}$ (Figure 3 ). The central feature is that it defines the geometric shape of the shell of double curvature (Miheev et al., 2011; Glushchenkov et al., 2012; Andreeva et al., 2016).

(iii) The features of the double curvature shell are taken into account, due to the fact that, when the surface is bent, it remains unchanged, as does its Gaussian curvature, although the principal curvatures vary inversely. For example, when the double-curvature shell obtained at the first skin is bent, the longitudinal curvature decreases and the transverse curvature increases (Figure 4). As a result, with the tightening punch attached to this shell shape, the 
localization of the deforming forces will be in the central cross section. Calculations performed using the analytical formulas given in allow us to determine the values of the expansion angle equal to $12^{\circ}$ for a given part. As a result, shaping by the tightness of the resulting deflection of the positioning pole of the shell relative to the tightening punch will allow deforming the edge regions in the same way as the pole in the first operation was deformed.

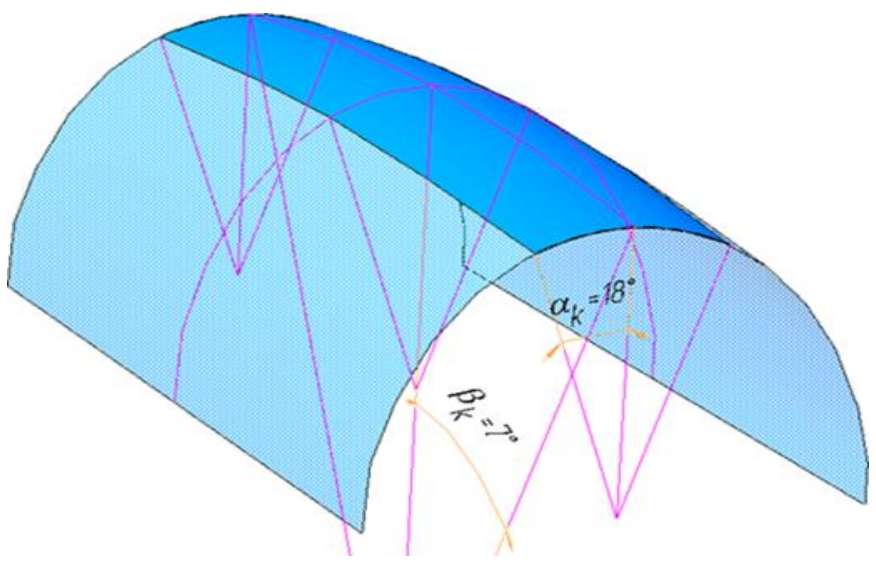

Figure 3. The central section of the shell

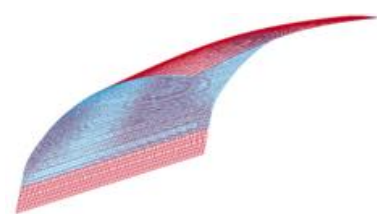

a)

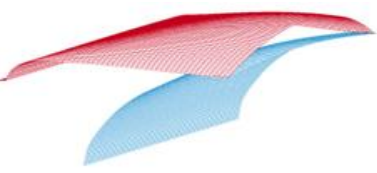

b)

Figure 4. Transverse deflection in the central part of the shell at the beginning of the extension of the double-curvature shell (a) obtained at the first skinning and at the end of the extension by $12^{\circ}$ (b)

Thus, the analysis of the causes made it possible to form three possible kinematic schemes of successive tightening, which combine the following force forming operations.

For the first kinematic scheme: a tightening of a cylindrical workpiece with an angle of engagement of the punch 900; bending of the part from 900 to 120 along the contour of the punch edge and stretching the part at an angle of 120; bending of the part without unloading along the molding contour of the punch with simultaneous extension of the part (Snegirev et al., 2016; Loktionova et al., 2016; Tribunskaia and Kozhukhov, 2017; Patsey and Galyshev, 2018).

For the second kinematic scheme: the tightening of a cylindrical blank with an angle of punch 180; bending of the part from 900 to 120 along the contour of the punch edge and stretching the part at an angle of 120; bending of the part without unloading along the molding contour of the punch. 
International Journal of Mathematical, Engineering and Management Sciences

Vol. 4, No. 4, 946-956, 2019

https://dx.doi.org/10.33889/IJMEMS.2019.4.4-075

For the third kinematic scheme: the tightening of the cylindrical workpiece with the angle of engagement of the punch 900; bending of the part from 900 to 120 along the contour of the punch edge and stretching the part at an angle of 120; free bending of the part along the molding contour of the punch; Calibration covering of the part with an angle of engagement of the punch 900 (Grechnikov and Khaimovich, 2015; Rakov et al., 2016; Gravit et al., 2018).

For the initial analysis of the results of numerical experiments conducted with the ANSYS / LSDYNA program, data were obtained for each of the three kinematic schemes, which correspond to different values of the friction coefficients $(0.05,0.1,0.2)$ when the anisotropic workpiece is tightened with coefficients transverse deformation and the distribution of effective deformations along the middle surface of the shell in the following stages: after the first hood at an angle of 90 or 180, after the workpiece has been bent at 120 and stretched, at the end of the molding operation; distribution of shell thickness at the given key stages.

\section{The Numerical Experiment}

We give one of the best variants of their three kinematic schemes.

The numerical experiment 1 (Figure 5).
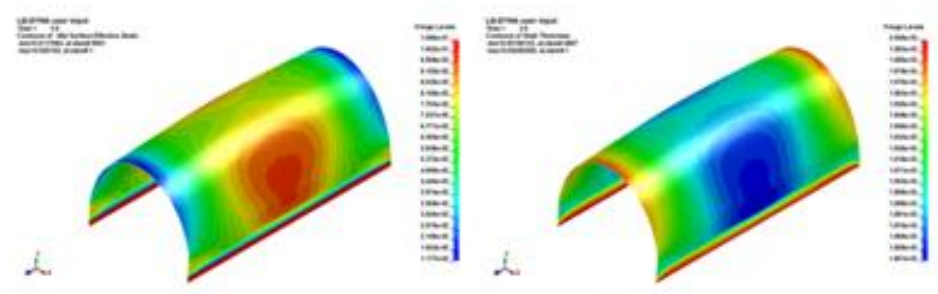

\section{a)}

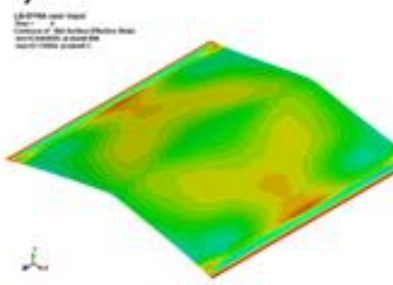

b)

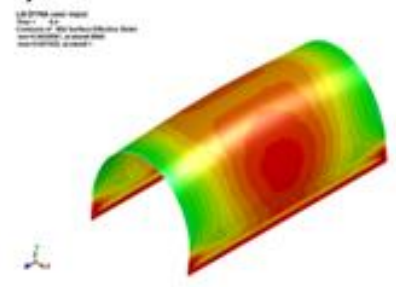

c)

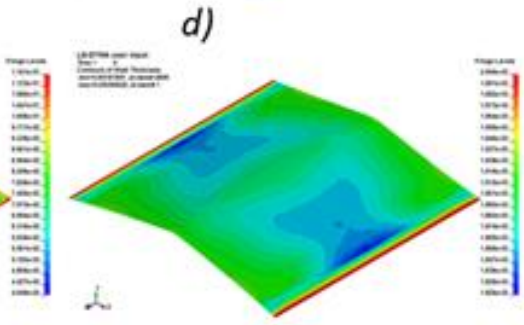

e)
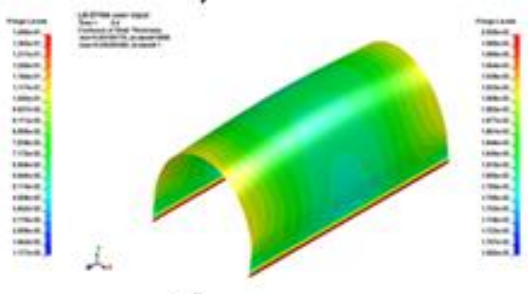

f)

Figure 5. Distributions of experimental data 1 from the first kinematic scheme in the following stages: after the first skinning by an angle of 900 (a, d), after the part is bent through the angle 120 and its extension (b,

e), at the end of the molding operation (c, f); a, b, c - distribution of effective deformations along the middle shell surface; $d, e, f$ is the shell thickness distribution 
International Journal of Mathematical, Engineering and Management Sciences

Vol. 4, No. 4, 946-956, 2019

https://dx.doi.org/10.33889/IJMEMS.2019.4.4-075

Numerical experiment 8 (Figure 6)

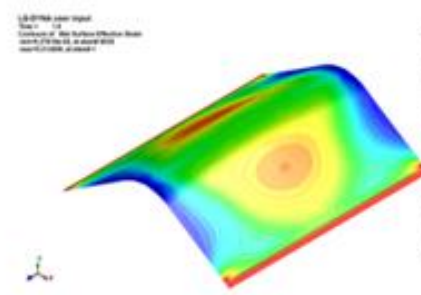

a)
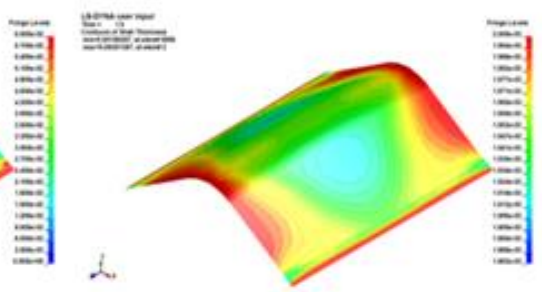

d)

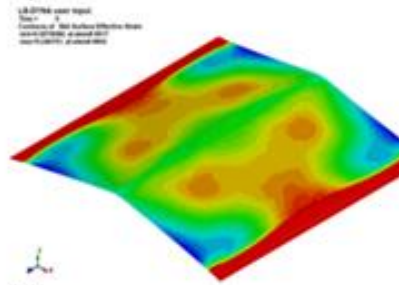

b)

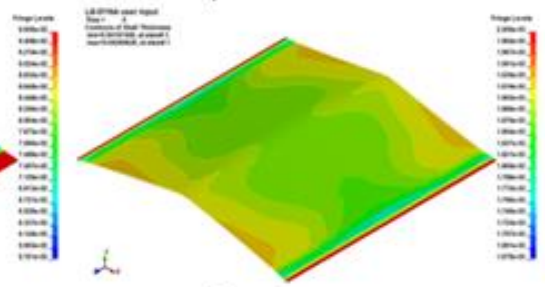

e)

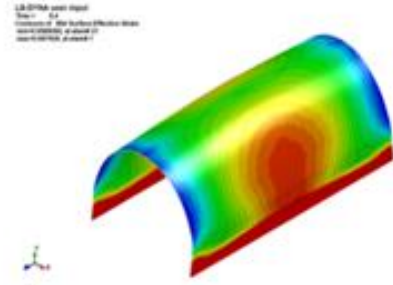

c)
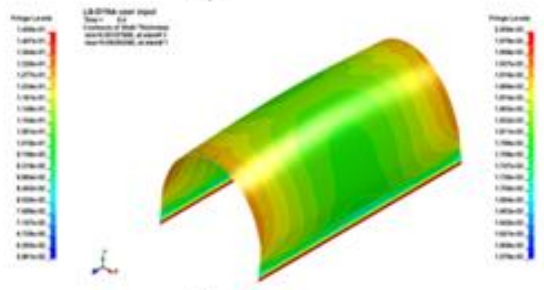

f)

Figure 6. Distributions of experimental data 8 from the second kinematic scheme in the following stages: after the first skinning by an angle of 180 (a, d), after the workpiece has been bent by 120 and stretched (b, e), at the end of the molding operation (c, f); $a, b, c$ - distribution of effective deformations along the middle shell surface; $d, e, f$ is the shell thickness distribution 
International Journal of Mathematical, Engineering and Management Sciences

Vol. 4, No. 4, 946-956, 2019

https://dx.doi.org/10.33889/IJMEMS.2019.4.4-075

Numerical experiment 14 (Figure 7)

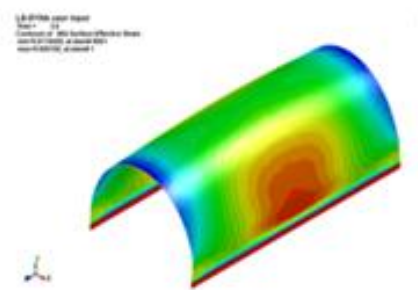

a)

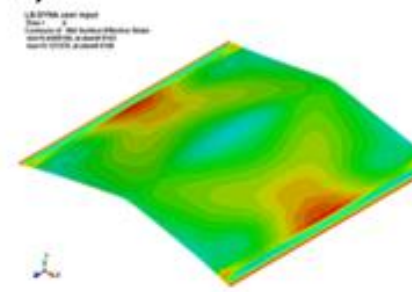

b)

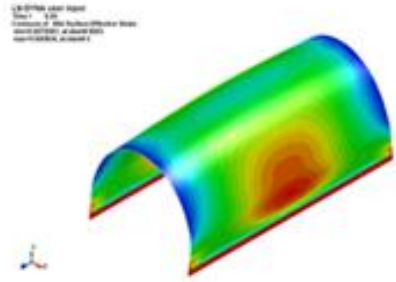

c)

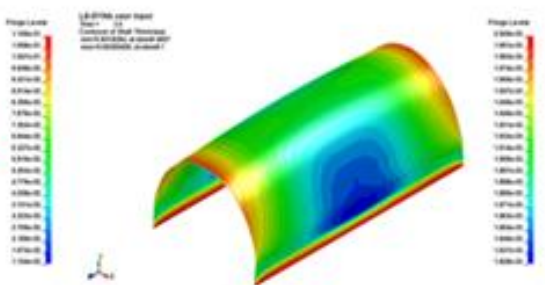

d)

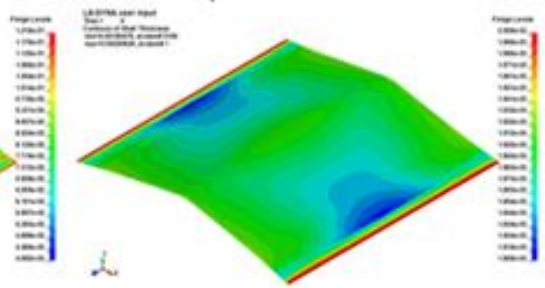

e)
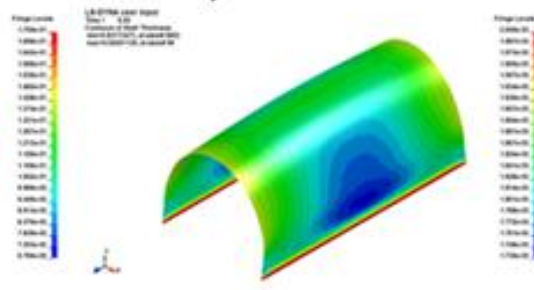

f)

Figure 7. Distributions of the experimental data 14 from the third kinematic scheme in the following stages: after the first skinning by an angle of 900 (a, d), after the part is bent through the angle 120 and its stretching (b, e), at the end of the molding operation (c, f); a, b, c - distribution of effective deformations along the middle shell surface; $d, e, f$ is the shell thickness distribution

\section{Results and Conclusions}

The analysis of friction coefficient values between the blank and the tightening punch and the anisotropy indices of the sheet billet and their changes in the technologically justified interval is performed. The coefficient of friction assumed the following values: $0.05,0.1$, and 0.2 . The anisotropy indices corresponded to the "less" textured $\mu_{21}=0.36, \mu_{21}=0.39, \mu_{1}=0.51$, and "more" textured $\mu_{21}=0.51, \mu_{21}=0.51, \mu_{1}=0.39$. As a result, a set of numerical experiments was formed depending on the number of kinematic schemes, friction coefficients and types of materials, depending on the degree of texture.

18 numerical experiments were performed, which allowed to reveal a more optimal kinematic scheme of forming by the skin of the double curvature shell, the probability of appearance of shell defects in the form of dangerous places in terms of deformation degree and possible corrugation on the surface was predicted. 
International Journal of Mathematical, Engineering and Management Sciences

Vol. 4, No. 4, 946-956, 2019

https://dx.doi.org/10.33889/IJMEMS.2019.4.4-075

The numerical experiments carried out provide complete information on the distribution of the shell thicknesses in the form of discrete values in one or another element. As a result, it became possible to perform statistical processing of this information, to reveal the nature of the distribution, the scope of the predicted values, and comparison with the tolerance for the thickness of the skin used at aviation enterprises.

\section{Conflict of Interest}

The authors confirm that there is no conflict of interest to declare for this publication.

\section{Acknowledgement}

The research carried out with the financial support of the grant from the Program Competitiveness Enhancement of Peter the Great St. Petersburg Polytechnic University.

\section{References}

Andreeva, N.V., Filimonov, A.V., Rudskoi, A.I., Burkhanov, G.S., Tereshina, I.S., Politova, G.A., \& Pelevin, I.A. (2016). A study of nanostructure magnetosolid $\mathrm{Nd}-\mathrm{Ho}-\mathrm{Fe}-\mathrm{Co}-\mathrm{B}$ materials via atomic force microscopy and magnetic force microscopy. Physics of the Solid State, 58(9), 1862-1869.

Andreeva, N.V., Naberezhnov, A.A., Tomkovich, M.V., Nacke, B., Kichigin, V., Rudskoy, A.I., \& Filimonov, A.V. (2016). Surface morphology and structure of double-phase magnetic alkali borosilicate glasses. Metal Science and Heat Treatment, 58(7-8), 479-482.

Apostolopoulos, C., Drakakaki, A., Apostolopoulos, A., Matikas, T., Rudskoi, A.I., \& Kodzhaspirov, G. (2017). Characteristic defects-corrosion damage and mechanical behavior of dual phase rebar. Materials Physics \& Mechanics, 30(1), 1-19.

Baimova, J.A., Murzaev, R.T., \& Rudskoy, A.I. (2017). Discrete breathers in graphane in thermal equilibrium. Physics Letters A, 381(36), 3049-3053.

Bulovich, S.V. (2017). Mathematical simulation of a gas flow in the vicinity of the open end of a tube for harmonic oscillations of a piston at the resonance frequency at the other end of the tube. Technical Physics, 62(11), 1634-1638.

Burkovsky, R.G., Bronwald, I., Andronikova, D., Wehinger, B., Krisch, M., Jacobs, J., Gambetti, D., Roleder, K., Majchrowski, A., Filimonov, A.V., Rudskoy, A.I., Vakhrushev, S.B., \& Tagantsev, A.K. (2017). Critical scattering and incommensurate phase transition in antiferroelectric $\mathrm{PbZrO}_{3}$ under pressure. Scientific Reports, 7, 41512.

Filin, A.P. (1987). Elements of the theory of covers (Vol. 3). L.: Stroyizdat. Leningr. otd-ny.

Galaev, S.A., Ris, V.V., Simoyu, L.L., \& Smirnov, E.M. (2017). Experience in numerical simulation of turbulent wet-steam flow in the last stage of a high-power condensing turbine under conditions defined by full-scale experiments at a power plant. 12th European Conference on Turbomachinery Fluid Dynamics and Thermodynamics, ETC 2017, Stockholm, Sweden.

Glouschenkov, V.A., Grechnikov, F.V., \& Malyshev, B.S. (1997). Pulse-magnetic processing technology when making parts and units of aerospace engineering. Le Journal de Physique IV, 7(C3), C3-45.

Glushchenkov, V.A., Grechnikov, F.V., Chernikov, D.G., \& Lazareva, A.A. (2012). Formation of electrocontact plugs of anodes of metallurgical production. Russian Journal of Non-Ferrous Metals, 53(1), 20-25. 
International Journal of Mathematical, Engineering and Management Sciences

Vol. 4, No. 4, 946-956, 2019

https://dx.doi.org/10.33889/IJMEMS.2019.4.4-075

Gravit, M.V., Terekh, M.D., Lyulikov, V.A., \& Svintsov, S.A. (2018, December). Software packages for calculation of fire resistance of building construction, including fire protection. In IOP Conference Series: Materials Science and Engineering (Vol. 456, No. 1, p. 012016). IOP Publishing.

Grechnikov, F. V., \& Khaimovich, A. I. (2015). Development of the requirements template for the information support system in the context of developing new materials involving Big Data. In CEUR Workshop Proceedings (Vol. 1490, pp. 364-375).

Grechnikov, F.V., Dem'yanenko, E.G., \& Popov, I.P. (2015). Development of the manufacturing process of aluminum alloys with high strength and conductance. Russian Journal of Non-Ferrous Metals, 56(1), 15-19.

Grechnikov, F.V., Noskova, E.A., \& Savel'eva, O.G. (2009). A study of the anisotropy of properties of sheet semiproducts from alloy AMg10. Metal Science and Heat Treatment, 51(7), 326-329.

Imayev, V., Gaisin, R., Rudskoy, A., Nazarova, T., Shaimardanov, R., \& Imayev, R. (2016). Extraordinary superplastic properties of hot worked $\mathrm{Ti}-45 \mathrm{Al}-8 \mathrm{Nb}-0.2 \mathrm{C}$ alloy. Journal of Alloys and Compounds, 663, 217-224.

Ivanov, N.V. (2018, January). A new approach to microstrip coupled-resonator bandpass filter design. In 2018 IEEE Conference of Russian Young Researchers in Electrical and Electronic Engineering (EIConRus) (pp. 201-203). IEEE.

Izamshah, R.A., Mo, J., \& Ding, S.L. (2011). Finite element analysis of machining thin-wall parts. In Key Engineering Materials (Vol. 458, pp. 283-288). Trans Tech Publications.

Kodzhaspirov, G., \& Rudskoi, A. (2017). The Effect of Thermomechanical Processing Temperature-StrainTime Parameters on the Mesostructure Formation. In Materials Science Forum (Vol. 879, pp. 24072412). Trans Tech Publications.

Leishman, R., Macdonald, J., Quebe, S., Ferrin, J., Beard, R., \& McLain, T. (2011, September). Utilizing an improved rotorcraft dynamic model in state estimation. In 2011 IEEE/RSJ International Conference on Intelligent Robots and Systems (pp. 5173-5178). IEEE.

Lisovenko, D.S., Baimova, J.A., Rysaeva, L.K., Gorodtsov, V.A., Rudskoy, A.I., \& Dmitriev, S.V. (2016). Equilibrium diamond-like carbon nanostructures with cubic anisotropy: Elastic properties. Physica Status Solidi (b), 253(7), 1295-1302.

Loktionova, E.A., Malyshevsky, D.Y., Schemelinin, D.I., \& Zaborova, D.D. (2016). Vertical distribution of compact air jets in the hall of an ice arena. In Advances and Trends in Engineering Sciences and Technologies II (pp. 549-554). CRC Press.

Miheev, V.A. (2003). The directed change of thickness of preparation at a formoobrazovaniye covering of obvodoobrazuyushchy covers of double curvature. ISTC Problems and prospects of development of engine-building, pp. 91.

Miheev, V.A., Grechnikova, A.F., \& Kuzina, A.A. (2011). Improvement of the processes of forming by the stretch-wrap forming of the shells of the dual curvature, News of the Samara Scientific Center of the Russian Academy of Sciences, 4(42), 2011, 217-224.

Musabirov, I.I., Safarov, I.M., Nagimov, M.I., Sharipov, I.Z., Koledov, V.V., Mashirov, A.V., Rudskoi, A.I. \& Mulyukov, R.R. (2016). Fine-grained structure and properties of a Ni 2 MnIn alloy after a settling plastic deformation. Physics of the Solid State, 58(8), 1605-1610.

Patsey, P., \& Galyshev, Y. (2018). Computational study of influence of inflow port channel design on sparkignition natural gas engine parameters. In MATEC Web of Conferences (Vol. 245, p. 09001). EDP Sciences. 
International Journal of Mathematical, Engineering and Management Sciences

Vol. 4, No. 4, 946-956, 2019

https://dx.doi.org/10.33889/IJMEMS.2019.4.4-075

Petrichenko, M., Nemova, D., Reich, E., Subbotina, S., \& Khayrutdinova, F. (2016). Heat and mass transfer in a vertical channel under heat-gravitational convection conditions. In EPJ Web of Conferences (Vol. 114, p. 02092). EDP Sciences.

Politova, G.A., Pankratov, N.Y., Vanina, P.Y., Filimonov, A.V., Rudskoy, A.I., Burkhanov, G.S., Ilyushi, A.S., \& Tereshina, I.S. (2019). Magnetocaloric effect and magnetostrictive deformation in Tb-Dy-GdCo-Al with Laves phase structure. Journal of Magnetism and Magnetic Materials, 470, 50-54.

Rakov, G., Rassokhin, V., Zabelin, N., Olennikov, S., Sebelev, A., Sukhanov, A., \& Schislyaev, S. (2016). A Low Emission Axial-Flow Turbine for the Utilization of Compressible Natural Gas Energy in the Gas Transport System of Russia. International Journal of Environmental \& Science Education, 11(18), 11721-11733.

Rudskoi, A.I., Kodzhaspirov, G.E., \& Kamelin, E.I. (2016). Simulation and prediction of the development of dynamic recrystallization during the deformation of low-alloy low-carbon steel blanks. Russian Metallurgy (Metally), 2016(10), 956-959.

Rudskoy, A.I., Kol'Tsova, T.S., Larionova, T.V., Smirnov, A.N., Vasil'Eva, E.S., \& Nasibulin, A.G. (2016a). Gas-phase synthesis and control of structure and thickness of graphene layers on copper substrates. Metal Science and Heat Treatment, 58(1-2), 40-45.

Rudskoy, A.I., Kondrat'ev, S.Y., \& Sokolov, Y.A. (2016b). New approach to synthesis of powder and composite materials by electron beam. Part 1 . Technological features of the process. Metal Science and Heat Treatment, 58(1-2), 27-32.

Rudskoy, A.I., Kodzhaspirov, G.E., Kliber, J., \& Apostolopoulos, C. (2016). Advanced metallic materials and processes. Materials Physics \& Mechanics, 25(1), 1-8.

Smirnov, E.M., Smirnovsky, A.A., Schur, N.A., Zaitsev, D.K., \& Smirnov, P.E. (2016, September). Numerical simulation of turbulent heat transfer past a backward-facing step: 2D/3D RANS versus IDDES solutions. In Journal of Physics: Conference Series (Vol. 745, No. 3, p. 032016). IOP Publishing.

Snegirev, A., Kokovina, E., Tsoy, A., Harris, J., \& Wu, T. (2016, September). The effect of soot modeling on thermal radiation in buoyant turbulent diffusion flames. In Journal of Physics: Conference Series (Vol. 745, No. 3, p. 032028). IOP Publishing.

Snegirev, A., Kuznetsov, E., Markus, E., Harris, J., \& Moravec, B. (2018, November). Performance and calibration of two subgrid extinction models for turbulent diffusion combustion in an under-ventilated enclosure fire. In Journal of Physics: Conference Series (Vol. 1107, No. 4, p. 042011). IOP Publishing.

Stepanov, M.D., Loboda, O.S., Novozhilov, Y.V., \& Vasilyev, N.V. (2017). Finite element modelling of the mitral valve repair using an implantable leaflet plication clip. Materials Physics and Mechanics, 32(3), 383-392.

Tribunskaia, K., \& Kozhukhov, Y.V. (2017, August). Analysis of Three-dimension Viscous Flow in the Model Axial Compressor Stage K1002L. In IOP Conference Series: Materials Science and Engineering (Vol. 232, No. 1, p. 012047). IOP Publishing.

Vasilyev, A.A., Kolbasnikov, N.G., Rudskoy, A.I., Sokolov, D.F., \& Sokolov, S.F. (2017). Kinetics of Structure Formation in the Heating of Cold-Rolled Automotive Steel Sheet. Steel in Translation, 47(12), $830-838$. 